\title{
ALTERAÇÕES NAS CARACTERÍSTICAS FÍSICAS DO MATERIAL ORGÂNICO SUBMETIDO AO PROCESSO DE COMPOSTAGEM
}

\author{
Denis Leocádio Teixeira ${ }^{1}$, Antonio Teixeira de $\mathrm{Matos}^{2}$, Evandro de Castro Melo
}

\section{RESUMO}

Neste trabalho, teve-se como objetivo avaliar as alterações físicas do material orgânico proporcionadas pelo processo de compostagem por leiras estáticas aeradas. Os resíduos utilizados foram constituídos pelas misturas dos agentes estruturantes bagaço de cana-de-açúcar e palha de café com cama de frango, com o objetivo de obter relações $\mathrm{C} / \mathrm{N}$ iniciais de 25/1. O material foi compostado, utilizando-se o sistema de leiras estáticas aeradas, por 30 dias, período de tempo em que se observou o final da fase termofílica. O processo de compostagem contribui para aumento da massa específica seca dos materiais em, aproximadamente, 12 e 13\%, respectivamente nos compostos que tinham o bagaço de cana-de-açúcar e a palha de café como agentes estruturantes. O volume inicial do material decresceu $60 \%$ na mistura cujo agente estruturante era o bagaço de cana-de-açúcar e 36\% quando utilizado a palha de café. A potência demandada pelo ventilador para superar a queda na pressão estática do ar ao atravessar a camada de material diminuiu com a compostagem, em decorrência da maior granulação do material.

Palavras-chave: resíduos sólidos, leiras estáticas aeradas, demanda de potência.

\section{ABSTRACT \\ CHANGES IN PHYSICAL CHARACTERISTICS OF ORGANIC MATERIAL SUBMITTED TO THE COMPOSTING PROCESS}

This study aimed to evaluate the physical changes of organic material provided by the compost process for aerated static piles. The wastes used were from mixture of the bulking agent sugarcane bagasse and coffee straw with chicken litter, in order to obtain the initial $\mathrm{C} / \mathrm{N}$ ratio of $25 / 1$. The material using the aerated static piles system was composted, for 30 days, at which time it was observed the end of thermophilic phase. The composting process contributed to increase the dry bulk density of the material in approximately 12 and 13\%, respectively for the mixture which the sugarcane bagasse and coffee straw were the bulking agents. The initial volume decreased $60 \%$ in the mixture which the bulking agent was sugarcane bagasse and 36\% when used the coffee straw. The power demanded by the fan to overcome the air static pressure drop imposed by material layer, decrease with the composting process, due the higher granulation of the material.

Keywords: solid waste, aerated static piles, power demand.

\section{Recebido para publicação em 01/07/2015. Aprovado em 08/03/2016.}

1 - Engenheiro Agrícola e Ambiental, Doutorando em Engenharia Agrícola na UFV, Viçosa-MG, denis.teixeira@ufv.br

2 - Engenheiro Agrícola, Professor do Departamento de Engenharia Sanitária e Ambiental, UFMG, Belo Horizonte-MG.

3 - Engenheiro Agrícola, Professor do Departamento de Engenharia Agrícola, DEA/UFV, Viçosa-MG 


\section{INTRODUÇÃO}

A produção de resíduos sólidos orgânicos, principalmente no setor agropecuário e nas agroindústrias, vem crescendo no Brasil. Segundo relatório do Instituto de Pesquisa Econômica Aplicada (IPEA, 2012) estima-se que, no ano de 2009, a geração de resíduos oriundos das agroindústrias associadas à agricultura foi de 291 milhões de toneladas. No que se refere a dejetos gerados na atividade pecuária, os valores são da ordem de 1,7 bilhões de toneladas, enquanto o setor florestal foi responsável por gerar, aproximadamente, 85 milhões de metros cúbicos de resíduos.

Resíduos provenientes da pecuária são frequentemente utilizados como fertilizantes orgânicos, porém, quando não dispostos na quantidade adequada, podem proporcionar emissões de gases de efeito estufa, perda de nitrogênio e contaminação dos solos e da água (ORRICO JÚNIOR et al., 2009).

Dentre as diversas formas de tratamento ou disposição de resíduos sólidos orgânicos, a compostagem, que se caracteriza por um método de tratamento com a finalidade de aproveitamento agrícola desses resíduos na forma de composto orgânico (COELHO et al., 2011; LASHERMES et al., 2012), destaca-se como uma das alternativas mais adequadas. De acordo com Almeida et al. (2012), dentre os diferentes métodos utilizados para compostagem, o sistema por leiras estáticas aeradas tem sido recomendado para processamento em grande escala.

O processo de compostagem provoca, no entanto, alterações nas características físicas e químicas do material orgânico, ocasionando redução de volume e de massa do material (PETRIC et al., 2009; ORRICO JÚNIOR et al., 2010). A resistência oferecida à passagem do ar através da camada de material orgânico, diretamente associada à quantidade de poros entre partículas, assim como da conectividade entre os mesmos (ALMEIDA et al., 2012), também é alterada ao longo do processo de compostagem, podendo influenciar na demanda de potência requerida pelo ventilador (MATOS et al., 2012).

Moreira et al. (2008), estudando a compostagem de bagaço de cana-de-açúcar picado misturado com cama de frango, observaram aumento na potência demandada pelo ventilador ao longo do período de compostagem, segundo os autores, devido ao aumento na massa específica do material. Paiva (2011), ao contrário, observou diminuição na potência demandada com o tempo de compostagem, devido à formação de maiores agregados com os "finos", degradação do material orgânico e diminuição no conteúdo de água livre na massa em compostagem, que fez o material diminuir de volume, desobstruindo os poros. Almeida et al. (2012), utilizando leiras estáticas aeradas para compostagem de resíduos da suinocultura, observaram decréscimo napotênciademandada pelo ventilador em relação ao tempo de compostagem, considerando a mesma taxa de aeração. Segundo os autores, a secagem da massa em compostagem ocasionada pela aeração proporcionou aumento no espaço poroso e, consequentemente, redução na resistência do ar ao atravessar o material. O aumento na permeabilidade, juntamente com a redução nos parâmetros inerciais, foi verificado até os 21 dias de compostagem, após esse tempo eles permaneceram constantes.

Sendo a potência demandada em sistemas de aeração forçada dependente das características físicas do material orgânico, as quais apresentam alterações ao longo do processo de compostagem, neste trabalho teve-se como objetivo avaliar as alterações físicas no material orgânico, proporcionadas pelo processo de compostagem em leiras estáticas aeradas, e relacionar essas alterações com a demanda de potência do ventilador.

\section{MATERIAL E MÉTODOS}

O trabalho experimental foi conduzido em um galpão coberto e com laterais fechadas, com aproximadamente $150 \mathrm{~m}^{2}$ de área, localizado na Área Experimental de Hidráulica, Irrigação e Drenagem do Departamento de Engenharia Agrícola da Universidade Federal de Viçosa, em Viçosa, Minas Gerais.

Os resíduos utilizados foram à cama de frango $(\mathrm{CF})$, importante resíduo da pecuária regional, e, como agentes estruturantes e fontes de carbono, o bagaço de cana-de-açúcar picado (BC) e a casca de 
frutos do cafeeiro ou palha de café (PC).

Visando a obtenção da relação $\mathrm{C} / \mathrm{N}$ de cada resíduo, determinou-se o teor de carbono orgânico total e de nitrogênio total. $O$ teor de carbono orgânico total foi quantificado conforme estabelecido no Método Oficial de Análises de Fertilizantes do Ministério da Agricultura, Pecuária e Abastecimento, apresentado na Instrução Normativa $n^{\circ} 28$, de 27 de julho de 2007 (BRASIL, 2007). Para a quantificação do teor de nitrogênio total foi utilizado o método semi-micro Kjeldahl (MATOS, 2012). Para a quantificação do conteúdo de água presente nos resíduos seguiu-se o procedimento padrão de estufa para materiais vegetais, com secagem a $60-65{ }^{\circ} \mathrm{C}$, por $24 \mathrm{~h}$, seguida de secagem monitorada a $100-105^{\circ} \mathrm{C}$ (MATOS, 2012).

Depois de quantificados os teores de nitrogênio total e carbono orgânico total de todos os resíduos, calculou-se a massa seca de cama de frango a ser misturada com os agentes estruturantes e fonte de carbono, de tal modo que as misturas apresentassem relação $\mathrm{C} / \mathrm{N}$ inicial em torno de 25/1. Em seguida, realizou-se a correção do conteúdo de água para $60 \mathrm{dag}^{\mathrm{kg}}{ }^{-1}$ (base úmida). Para a compostagem desse material, foi utilizado o sistema de leiras estáticas aeradas, por 30 dias, período de tempo suficiente para que ocorresse a fase termofílica, que foi considerada findada quando a relação $\mathrm{C} / \mathrm{N}$ do material passou a ser menor que $18 / 1$ e a temperatura das pilhas menor que $40{ }^{\circ} \mathrm{C}$ (PAIVA et al., 2012). Durante o período de compostagem, as leiras foram desmontadas semanalmente para correção do conteúdo de água.

As leiras foram construídas utilizando-se seção triangular com $1,5 \mathrm{~m}$ de base, $1 \mathrm{~m}$ de altura e 2 $\mathrm{m}$ de comprimento, sendo que cada leira possuía um ventilador centrífugo (motor elétrico de $3 / 4 \mathrm{cv}$ de potência). $\mathrm{O}$ funcionamento dos ventiladores seguiu as recomendações de Paiva (2011), ou seja, cada ventilador era acionado por meio de um termostato digital, sempre que a temperatura da massa, no centro da leira, atingia $65^{\circ} \mathrm{C}$ e, uma vez que, com a aeração, a temperatura da massa ia diminuindo sempre que ela atingia $55^{\circ} \mathrm{C}$, o conjunto moto-ventilador era desligado.

Para acompanhamento da degradação dos resíduos durante o processo de compostagem, além da relação $\mathrm{C} / \mathrm{N}$, também foram monitoradas as concentrações de sólidos voláteis, variável utilizada para medir o grau de estabilização e mineralização da matéria orgânica. A concentração de sólidos voláteis foi obtida após calcinação do material em mufla, sob temperatura de $550{ }^{\circ} \mathrm{C}$, por 2 h (MATOS, 2012).

A massa específica úmida do composto orgânico foi obtida dividindo-se a massa necessária para completar um recipiente circular com diâmetro de $0,8 \mathrm{~m}$ e altura de $1 \mathrm{~m}$, pelo respectivo volume da leira de compostagem. $\mathrm{O}$ acondicionamento do material na coluna foi realizado de forma gradual, em camadas de $10 \mathrm{~cm}$ de espessura, com altura de queda do material fixada em $1 \mathrm{~m}$. A massa específica seca foi calculada a partir da massa específica úmida e do conteúdo de água presente.

A potência demandada pelo ventilador foi calculada considerando-se apenas a potência demandada para vencer a queda na pressão estática do ar imposta por uma camada de material de $1 \mathrm{~m}$ de altura, considerando-se uma taxa de aeração de $1200 \mathrm{~m}^{3} \mathrm{~h}^{-1} \mathrm{t}^{-1}$ (PINTO, 2001) e o rendimento do ventilador de $60 \%$, conforme a Equação 1.

Pot $=\frac{P_{\text {total }} Q}{\eta}$

em que,

Pot $=$ potência elétrica absorvida pelo ventilador (W);

$\mathrm{P}_{\text {total }}=$ pressão estática a ser fornecida pelo ventilador $(\mathrm{Pa})$;

$\mathrm{Q}=$ vazão de $\operatorname{ar}\left(\mathrm{m}^{3} \mathrm{~s}^{-1}\right), \mathrm{e}$

$\eta=$ rendimento do ventilador, considerado igual a $60 \%$ (adimensional).

Para determinação da queda de pressão estática do ar, ao atravessar as camadas de material orgânico em compostagem, utilizou-se um micro manômetro digital marca - KIMO, modelo - MP 120 , com resolução de 0,1 mmca e faixa de medição de 0 a 100 mmca. As medições foram realizadas na tubulação de ar, em um ponto próximo a leira, conforme a Figura 1. 


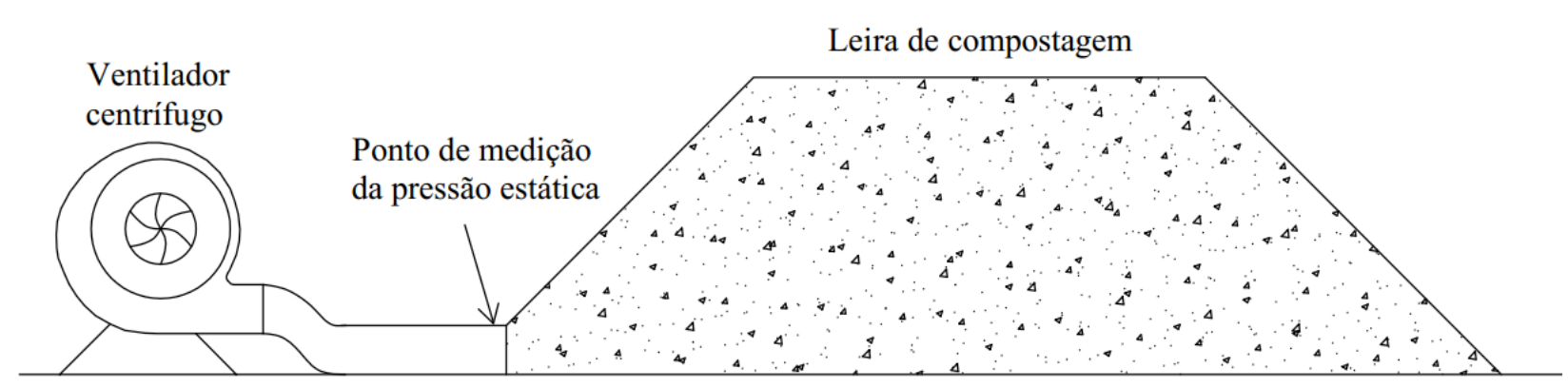

Figura 1. Ponto de medição da pressão estática do ar.

\section{RESULTADOS E DISCUSSÃO}

Os valores de relação $\mathrm{C} / \mathrm{N}$, teor de sólidos voláteis, massa específica e conteúdo de água para as misturas de bagaço de cana-de-açúcar com cama de frango e palha de café com cama de frango, antes e depois de terem sido submetidos ao processo de compostagem, estão apresentados no Quadro 1.

A proporção, em base volumétrica, de cama de frango adicionada ao bagaço de cana-de-açúcar e palha de café para obtenção de relação $\mathrm{C} / \mathrm{N}$ de $29 / 1$ e $21 / 1$, foram de 11 e $8 \%$, respectivamente. Já os valores de relação $\mathrm{C} / \mathrm{N}$ da cama de frango, palha de café e bagaço de cana-de-açúcar foram de 9,$5 ; 31,1$ e 182,7, respectivamente. Observase que a relação $\mathrm{C} / \mathrm{N}$ no material após a mistura apresentou uma pequena variação em relação ao valor estabelecido inicialmente, que foi de 25/1, sendo a heterogeneidade do material a principal responsável por essa variação. Acredita-se que a proporção em termos de massa ou volume entre diferentes resíduos, visando-se alcançar uma relação $\mathrm{C} / \mathrm{N}$ ideal para início do processo de compostagem, varia de acordo com a constituição química dos materiais misturados, assim não existem proporções únicas nas diferentes misturas de resíduos, uma vez que essa proporção é definida com base nos teores de carbono e nitrogênio, massa específica e conteúdo de água presente nos materiais.

O conteúdo de água no material, antes do processo de compostagem, variou em torno de $60 \mathrm{dag}^{\mathrm{kg}}{ }^{-1}$, considerado ideal, segundo Paiva et al. (2012) para o processo de compostagem em leiras estáticas aeradas. No material compostado, proveniente da mistura de bagaço de cana-deaçúcar e cama de frango, o conteúdo de água na fase final do processo ficou acima dos valores recomendados, no entanto, devido à boa granulação do material, isso não trouxe prejuízos ao processo de compostagem.

A massa específica obtida com o produto úmido é influenciada pelo conteúdo de água presente no material (HUERTA-PUJOL et al., 2010), desse modo, recomenda-se analisar a massa específica seca, condição em que não há influência do conteúdo de água no material. Huerta-Pujol et al. (2010) não encontraram diferença significativa entre a massa específica úmida, ao longo do processo de compostagem de resíduos sólidos urbanos, no entanto, verificou-se aumento considerável quando analisada a massa específica seca.

De acordo com os resultados apresentados no Quadro 1, a massa específica seca das misturas de materiais antes e depois do processo de compostagem, apresentou aumento de, aproximadamente, 12 e $13 \%$ nessa variável para o composto preparado com bagaço de cana-de-açúcar e com palha de café, respectivamente. Matos et al. (2012) encontraram para palha de café misturada com cama de frango razão entre massas de 2,5:1 (proporção de $28,6 \%$ de cama de frango), massas específicas secas de 142 e $218 \mathrm{~kg} \mathrm{~m}^{-3}$, considerando o material antes e depois de ser submetido ao processo de compostagem. A massa específica obtida pelos autores no início do processo de compostagem foi praticamente igual à obtida neste trabalho, na fase final do processo. Moreira et al. (2008) obtiveram, para o bagaço de cana-de-açúcar misturado com cama de frango ( $38 \%$ em volume), após 30 dias de compostagem, massa específica seca de $215 \mathrm{~kg} \mathrm{~m}^{-3}$, diferindo consideravelmente da obtida neste trabalho, embora seja importante ressaltar que foram utilizadas proporções diferentes

\section{REVENG} $41-49 p$. 
Quadro 1. Relação C/N, teor de sólidos voláteis, massa específica e conteúdo de água (base úmida) no material antes e depois do processo de compostagem.

\begin{tabular}{|c|c|c|c|c|c|c|}
\hline \multirow[t]{2}{*}{ Estádio } & \multirow[t]{2}{*}{ Resíduo } & \multirow{2}{*}{$\begin{array}{c}\text { Relação } \\
\text { C/N }\end{array}$} & \multirow{2}{*}{$\begin{array}{l}\text { Sólidos Voláteis } \\
\quad\left(\text { dag } \mathrm{kg}^{-1}\right)\end{array}$} & \multicolumn{2}{|c|}{$\begin{array}{l}\text { Massa Específica } \\
\qquad\left(\mathrm{kg} \mathrm{m}^{-3}\right)\end{array}$} & \multirow{2}{*}{$\begin{array}{l}\text { Conteúdo de Água } \\
\quad\left({\left.\text { dag } \mathrm{kg}^{-1}\right)}^{-1}\right.\end{array}$} \\
\hline & & & & Úmida & Seca & \\
\hline Antes & $\mathrm{BC}+\mathrm{CF}$ & 29,3 & 81,2 & 264 & 101 & 61,8 \\
\hline compostagem & $\mathrm{PC}+\mathrm{CF}$ & 21,3 & 72,7 & 317 & 126 & 60,2 \\
\hline Depois & $\mathrm{BC}+\mathrm{CF}$ & 13,1 & 59,3 & 377 & 113 & 70,1 \\
\hline compostagem & $\mathrm{PC}+\mathrm{CF}$ & 15,1 & 62,3 & 309 & 143 & 53,7 \\
\hline
\end{tabular}

Em que, $(\mathrm{BC}+\mathrm{CF})$ bagaço de cana-de-açúcar e cama de frango; $(\mathrm{PC}+\mathrm{CF})$ palha de café e cama de frango.

de cama de frango na mistura.

Grande parte dos resíduos utilizados como agentes estruturantes, quando umedecidos, apresentam redução significativa na resistência oferecida à compactação, principalmente quando o conteúdo de água está dentro da faixa recomendada para compostagem, desse modo, foi observada a formação de camadas compactadas na base das leiras de compostagem, devido à compressão proporcionada pelo peso próprio do material e ao seu aumento de peso. De acordo com Huet et al. (2012), após a montagem da pilha de compostagem, verifica-se aumento na massa específica do material com a profundidade da camada, enquanto que o espaço poroso e a permeabilidade diminuem.

A degradação do material orgânico ao longo do processo de compostagem, além de contribuir para o aumento na massa específica do material, influenciou na redução do volume da pilha de material em compostagem. $\mathrm{O}$ volume de material presente no início do processo de compostagem foi de $1,5 \mathrm{~m}^{3}$ para cada mistura, sendo verificado, ao término do processo, um volume de $0,59 \mathrm{~m}^{3} \mathrm{de}$ composto em que o agente estruturante era o bagaço de cana-de-açúcar e $0,96 \mathrm{~m}^{3}$ quando era a palha de café. Assim, houve redução de aproximadamente $60 \%$ no volume inicial, na mistura cujo agente estruturante era o bagaço de cana-de-açúcar e $36 \%$ quando utilizado a palha de café.

Diversos são os fatores que influenciam na redução de volume do material em processo de compostagem. A redução de volume observado em uma massa em compostagem é dividida em dois estágios, nos primeiros dias de compostagem ocorre a redução física, proveniente da compactação do material (HUET et al., 2012), e, posteriormente, a redução proveniente da perda de massa em função da degradação do material orgânico e da perda de água do material (ORRICO JÚNIOR et al., 2010). A maior redução de volume observada para o bagaço de cana-de-açúcar está relacionada com a redução física do material, o qual é mais susceptível à compactação, quando comparado com a palha de café.

Em sistemas de compostagem por leiras estáticas aeradas, tem sido observada redução tanto de volume como de massa do material. A redução no volume de material ao longo do processo de compostagem varia com o tipo de sistema adotado, segundo Yue et al. (2008), dentre os sistemas de compostagem por aeração natural, leiras estáticas aeradas e sistema Windrow, o último proporciona maior redução de volume no material, que pode chegar a até $83 \%$ do volume inicial. Yue et al. (2008), ao estudarem a compostagem de lodo de esgoto misturado com palha de milho e serragem de madeira, observaram maior redução de volume no material em que a mistura do lodo foi feita com palha de milho, e que o aumento na proporção do agente estruturante na mistura proporcionava menores reduções no volume do material, ao longo do processo de compostagem. Orrico Júnior et al. (2009), ao utilizarem a fração sólida da água residuária de suinocultura como substrato para compostagem em sistemas Windrow, observaram que a redução de volume apresentava comportamento quadrático, com redução acentuada nas primeiras semanas de processamento, seguida de desaceleração gradual até o fim do processo. A redução de volume observada pelos autores ao final do processo chegou a $64,5 \%$ do volume inicial. 

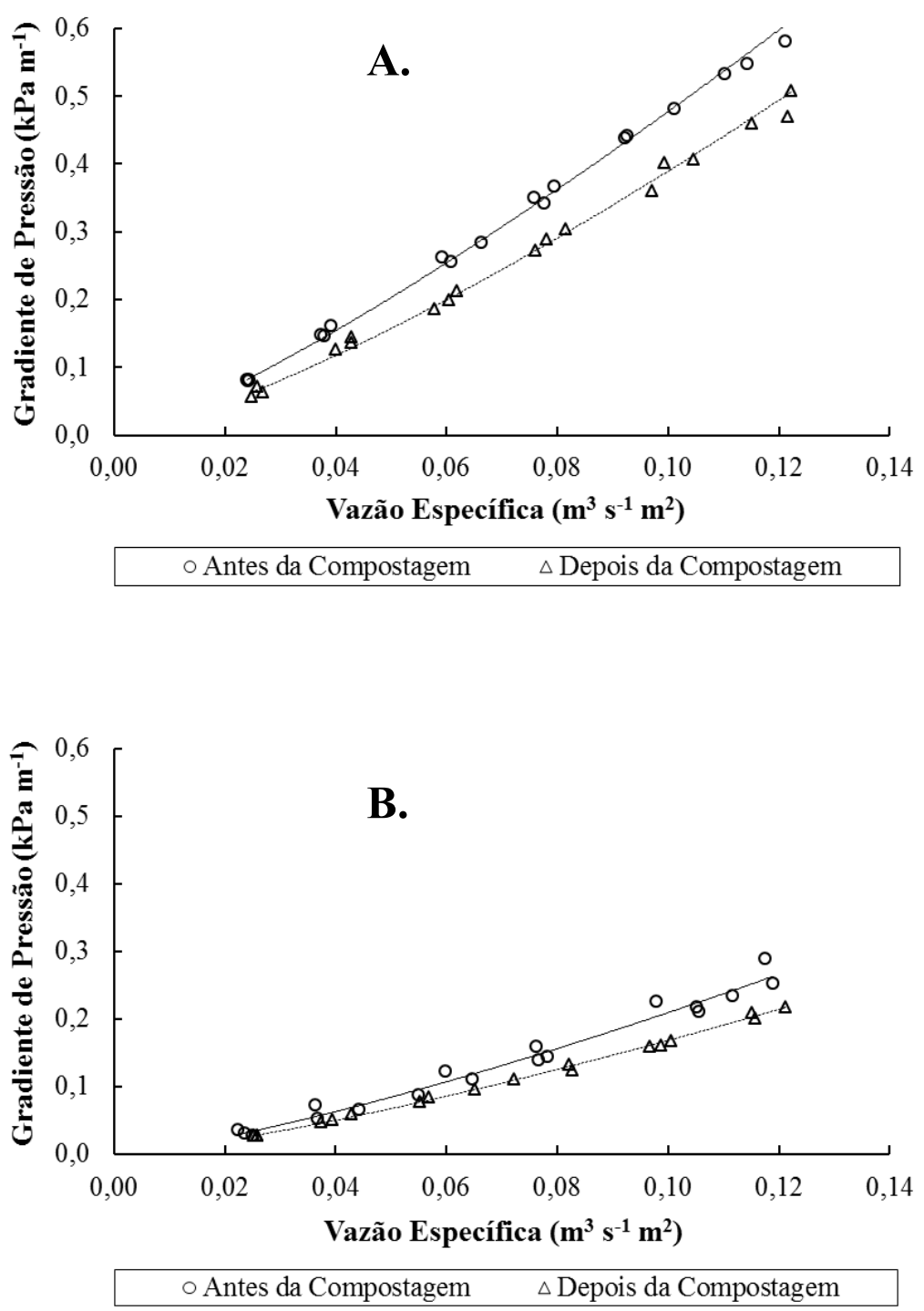

Figura 2. Gradiente de pressão estática do ar em camada de cama de frango misturada com bagaço de cana-de-açúcar (A) e palha de café (B), antes e depois de ter sido submetido ao processo de compostagem, em função da vazão específica de ar.

A resistência oferecida à passagem do ar através de uma camada de material orgânico é quantificada pelo gradiente de pressão, por meio da queda na pressão estática do ar por unidade de espessura da camada de material, que varia em função da vazão específica de ar aplicada. O gradiente de pressão estática em função da vazão específica do ar, para as misturas de cama de frango com bagaço de canade-açúcar e palha de café, antes e depois de terem sido submetidas ao processo de compostagem, estão apresentados na Figura 2.

As alterações no material influenciam na demanda de potência exigida pelo ventilador, desse modo foi calculada a potência demandada para superar a queda na pressão estática do ar imposta pela camada de material com $1 \mathrm{~m}$ de altura (Quadro 2).

De acordo com os resultados apresentados no Quadro 2, observa-se que a mistura que teve o bagaço de cana-de-açúcar como agente estruturante foi o que proporcionou maior demanda de potência, sendo aproximadamente duas vezes superior à observada quando a palha de café foi utilizada como agente estruturante, considerando-se mesma taxa de aeração.

A menor demanda de potência, verificada quando utilizada a palha de café como agente estruturante, pode estar relacionada à geometria do

\section{REVENG 41-49p.}


Quadro 2. Demanda de potência do ventilador para aeração do material antes e depois de ter sido submetido ao processo de compostagem.

\begin{tabular}{llc}
\hline Estádio & Resíduo & Potência Demandada $\left(\mathrm{W} \mathrm{t}^{-1}\right)$ \\
\hline \multirow{2}{*}{ Antes da compostagem } & $\mathrm{BC}+\mathrm{CF}$ & 72,0 \\
& $\mathrm{PC}+\mathrm{CF}$ & 37,1 \\
\multirow{2}{*}{ Depois da compostagem } & $\mathrm{BC}+\mathrm{CF}$ & 62,9 \\
& $\mathrm{PC}+\mathrm{CF}$ & 35,1 \\
\hline
\end{tabular}

Em que, $(\mathrm{BC}+\mathrm{CF})$ bagaço de cana-de-açúcar e cama de frango; $(\mathrm{PC}+\mathrm{CF})$ palha de café e cama de frango.

resíduo, o que proporciona a formação de grandes espaços porosos entre as partículas do material, quando empilhado. Outro fator importante é o aspecto de concha do material, decorrente da sua condição de fruta aproximadamente esférica ou elipsoidal. As cavidades convexas, presentes na maioria das cascas, podem ser preenchidas com materiais finos, como a cama de frango, porém sem obstruir significativamente os espaços porosos do material e, consequentemente, proporcionar resistência à passagem do ar (Figura 2).

Moreira et al. (2008), considerando a taxa de aeração de $1200 \mathrm{~m}^{3} \mathrm{~h}^{-1} \mathrm{t}^{-1}$ recomendada por Pinto (2001), na aeração de cama de frango misturado com bagaço de cana-de-açúcar, verificaram que a demanda de potência requerida pelo ventilador, aos 30 dias de compostagem do material, em camada de $1 \mathrm{~m}$ de altura, foi de 44,2 $\mathrm{W} \mathrm{t}^{-1}$. Matos et al. (2012), obtiveram para aeração de cama de frango misturada com palha de café, antes do material ser submetido ao processo de compostagem, demanda de potência de $1,2 \mathrm{~W} \mathrm{t}^{-1}$ para camada com espessura de $1 \mathrm{~m}$. Paiva (2011), utilizando leiras estáticas aeradas na compostagem de carcaças de frango juntamente com palha de café e cama de frango, obteve demanda de potência média de $274 \mathrm{~W} \mathrm{t}^{-1}$, ao longo do processo de compostagem da mistura de material orgânico em leiras estáticas aeradas, em espessura de camada em torno de $0,9 \mathrm{~m}$. Nesse experimento, foram monitoradas 3 leiras estáticas aeradas, sendo a demanda de potência máxima observada para cada leira de 574,$8 ; 513,8$ e $329 \mathrm{~W}$ $\mathrm{t}^{-1}$. A demanda de potência obtida neste trabalho está condizente com os valores encontrados pelo citado autor, porém todos os valores estão abaixo de $820,6 \mathrm{~W} \mathrm{t}^{-1}$, valor citado por Pinto (2001) para a compostagem aerada de lodo de esgoto.
O conhecimento da potência demandada pelo ventilador ao longo do processo de compostagem é essencial no dimensionamento do sistema de aeração, uma vez que influencia diretamente na eficiência do processo e no consumo de energia (ALMEIDA et al., 2012). O processo de compostagem contribuiu para redução da potência demandada pelo ventilador, tanto no que se refere à mistura em que o bagaço de cana-de-açúcar era o agente estruturante como na mistura que possuía a palha de café. Assim como observado por PAIVA (2011), acredita-se que um dos principais motivos para isso seja a tendência de estruturação do material na forma de grânulos, os quais proporcionam a formação de grande espaço poroso e, com isso, pequena resistência à passagem do ar através do material. Outro motivo seria a diminuição do volume da leira de compostagem e, consequentemente, da espessura de material o qual o ar é forçado a passar.

\section{CONCLUSÕES}

- O processo de compostagem contribuiu para aumento na massa específica seca das misturas de bagaço de cana-de-açúcar ou palha de café com cama de frango em, aproximadamente, 12 e $13 \%$, respectivamente.

- Houve redução de $60 \%$ no volume inicial da mistura cujo agente estruturante era o bagaço de cana-de-açúcar e de $36 \%$ quando era a palha de café.

- A potência demandada pelo ventilador para aeração de camadas com $1 \mathrm{~m}$ de espessura de material proveniente do bagaço de canade-açúcar e da palha de café diminuiu com o 
processo de compostagem, sendo de 72,0 e $37,1 \mathrm{~W} \mathrm{t}^{-1}$, no início do processo, e de $62,9 \mathrm{e}$ $35,1 \mathrm{~W} \mathrm{t}^{-1}$, depois de 30 dias de compostagem, respectivamente.

- Os resultados obtidos indicaram ser o ventilador dimensionado para o início do processo, suficiente para adequada aeração do material ao final do processo.

\section{REFERÊNCIAS BIBLIOGRÁFICAS}

ALMEIDA, P.; SILVEIRA, A.; MIGUEL, A.F. Applicability of the Forchheimer equation for forced-aeration windrow composting: variation of airflow characteristics with humidity and volatile solids. Fluid Mechanics Research, v.39, p.149159, 2012.

BRASIL. Ministério da Agricultura, Pecuária e Abastecimento. Instrução Normativa ${ }^{\circ} 28$, de 27 de julho de 2007. Aprova os métodos analíticos oficiais para fertilizantes minerais, orgânicos, organo-minerais e corretivos, disponíveis na Coordenação-Geral de Apoio Laboratorial CGAL/SDA/MAPA, na Biblioteca Nacional de Agricultura - BINAGRI e no sítio do Ministério da Agricultura, Pecuária e Abastecimento. Diário Oficial da República Federativa do Brasil, Brasília, 31 de julho de 2007.

COELHO, C.; CAVANI, L.; HALlE, A.T.; GUYOT, G.; CIAVATTA, C.; RICHARD, C. Rates of production of hydroxyl radical and singlet oxygen from irradiated compost. Chemosphere, v.85, p.630-636, 2011.

HUERTA-PUJOL, O.; SOLIVA, M.; MARTÍNEZFARRÉ, F.X.; VALERO, J.; LÓPEZ, M. Bulk density determination as a simple and complementary tool in composting process control. Bioresource Technology, v.101, p.9951001, 2010.

HUET, J.; DRUILHE, C.; TRÉMIER, A.; BENOIST,J.C.; DEBENEST, G.The impact of compaction, moisture content, particle size and type of bulking agent on initial physical properties of sludge-bulking agent mixtures before composting. Bioresource Technology, v.114, p.428-436, 2012.

IPEA. INSTITUTO DE PESQUISA ECONÔMICA APLICADA. Diagnóstico dos resíduos orgânicos do setor agrossilvopastoril e agroindústrias associadas. Relatório de Pesquisa, Brasília, 2012. $134 \mathrm{p}$.

LASHERMES, G.; BARRIUSO, E.; HOUOT, S. Dissipation pathways of organic pollutants during the composting of organic wastes. Chemosphere, v.87, p.137-143, 2012.

MATOS, A.T. Qualidade do Meio Físico Práticas de laboratório.Viçosa, MG: Editora UFV, 2012. 150p.

MATOS, A.T.; TEIXEIRA, D.L.; RIBEIRO, I.C.; PAIVA, E.C.R.; LACERDA FILHO, A.F. Demanda de potência do ventilador para aeração de material em compostagem. Engenharia Agrícola, Viçosa, MG, v.32, n.3, p.542-551, 2012.

MOREIRA, D.A.; MATOS, A.T.; SARTORI, M.; SILVA, N.C.L.; BARROS, R.T.P.; LUÍS, F.A.R. Perda de carga no fluxo de ar forçado em colunas de material orgânico com diferentes profundidades e estádios de degradação bioquímica. Engenharia na Agricultura, Viçosa, MG, v.16, p.238-247, 2008.

ORRICO JÚNIOR, M.A.P.; ORRICO, A.C.A.; LUCAS JÚNIOR, J. Compostagem dos resíduos da produção avícola: cama de frangos e carcaças de aves. Engenharia Agrícola, Jaboticabal, v.30, n.3, p.538-545, 2010.

ORRICO JÚNIOR, M.A.P.; ORRICO, A.C.A.; LUCAS JÚNIOR, J. Compostagem da fração sólida da água residuária de suinocultura. Engenharia Agrícola, Jaboticabal, v.29, n.3, p.483-491, 2009.

PAIVA, E.C.R. Variáveis de projeto, operação de sistemas de leiras estáticas aeradas e qualidade do composto produzido com carcaças de aves mortas. 2011. 112f. Tese (Doutorado em Engenharia 
Agrícola) - Universidade Federal de Viçosa, Viçosa, MG, 2011.

PAIVA, E.C.R.; MATOS, A.T.; AZEVEDO, M.A.; BARROS, R.T.P.; COSTA, T.D.R. Avaliação da compostagem de carcaças de frango pelos métodos da composteira e de leiras estáticas aeradas. Engenharia Agrícola, Jaboticabal, v.32, n.5, p.961-970, 2012.

PETRIC, I.; SESTAN, A.; SESTAN, I. Influence of wheat straw addition on composting of poultry manure. Process Safety and Environmental Protection, v.87, p.206-2012, 2009.

PINTO, M.T. Higienização de lodos.In: ANDREOLI et al. (Ed.). Lodo de esgotos: tratamento e disposição final. Belo Horizonte: DESA-UFMG/SANEPAR, 2001. p.261-317.

YUE, B.; CHEN, T.B.; GAO, D.; ZHENG, G.D.; LIU, B.; LEE, D.J. Pile settlement and volume reduction measurement during forced-aeration static composting. Bioresource Technology, v.99, p.7450-7457, 2008. 